\section{Prevalence and Antibiotic Sensitivity Pattern of Staphylococcus aureus Isolates of Non-Hospital Origin}

\section{Abstract}

Title: Antibiogram of Staphylococcus aureus isolates bacteriologically recovered from urine samples of pupils.

Background: The emergence and spread of strains of $S$. aureus that are resistant to some first line antibiotics is of public health importance. Staphylococcus aureus is ubiquitously found in the environment as a commensal organism, but pathogenic strains of the bacterium that are resistant to some commonly available antibiotics puts antimicrobial therapy at risk. This study reports the prevalence and sensitivity of $S$. aureus from primary school pupils.

Methods and findings: A total of 25 urine samples were collected and bacteriologically analyzed for the isolation of $S$. aureus isolates. The antibiogram of the S. aureus isolates was carried out using the Kirby-Bauer disk diffusion method as per the CLSI guideline. Statistical analysis was carried out using SPSS. Out of 25 urine samples screened for the isolation of S. aureus, $22(88 \%)$ of them were confirmed positive. S. aureus was found to be higher in females 12 (93.3\%) compared to males ( $n=10 ; 83.3 \%$ ). In females, the occurrence of $S$. aureus isolates was highest among pupils aged $\leq 7$ years $(n=6 ; 100 \%)$, and this was followed by pupils aged $8-10$ years $(n=4 ; 80 \%)$. S. aureus isolates was least recovered from urine samples of pupils aged $\geq 12$ years $(n=2 ; 100 \%)$. There was no statistical difference in the rate of isolation of $S$. aureus isolates in relation to the age and sex of the pupils recruited for this study. The $S$. aureus isolates were resistant or intermediately resistant to ampicillin (77.2\%), chloramphenicol $(72.2 \%)$, ampicillin (77.2\%) and levofloxacin (59.0\%). But they were considerably sensitive to gentamicin (77.2\%) and ciprofloxacin (72.7\%).

Conclusions: Our study has shown that $S$. aureus isolates from apparently healthy pupils are drug resistant in nature. We recommend a periodic screening of environmental isolates of $S$. aureus in order to contain any disease outbreak due to drug resistant $S$. aureus isolates.

Keywords: Staphylococcus aureus; Community-acquired infections; Antibiogram; Urine samples; Nigeria
Okonkwo EC'", Orji JO', Aondloackaa AD², Ugbo EN', Moses IB ${ }^{1}$, Ogene $L^{1}$ and Nwuna EN ${ }^{1}$

1 Department of Applied Microbiology, Ebonyi State University, Abakaliki, P.M.B. 053, Ebonyi State, Nigeria

2 Department of Microbiology, College of Science, Federal University of Agriculture, Makurdi, Nigeria

*Corresponding author: Okonkwo EC

戸 okonkwoeucharia2@gmail.com

Department of Applied Microbiology, Ebonyi State University, Abakaliki, P.M.B 053, Ebonyi State, Nigeria.

Tel: 08069657623

Citation: Okonkwo EC, Orji JO, Aondoackaa AD, Ugbo EN, Moses IB, et al. (2018) Prevalence and Antibiotic Sensitivity Pattern of Staphylococcus aureus Isolates of Non-Hospital Origin. Arch Clin Microbiol. Vol.9 No.1:76

Received: February 01, 2018; Accepted: February 18, 2018; Published: February 23, 2018

\section{Introduction}

Staphylococcus aureus is a facultative anaerobic Gram-positive coccus that is normal flora of the human nose, skin and mucous membranes [1,2]. However, pathogenic strains of the bacterium have been implicated in a number of bacterial related infections including but not limited to bacteraemia, sepsis and skin infections. S. aureus is the most common species of the genus Staphylococcus that causes staphylococcal infections in man. Staphylococcus aureus has emerged as an important human pathogen, and it has over the past decades been a leading foundation of hospital and community acquired infections [3-5]. 
The carriage of Staphylococcus aureus is an important source of nosocomial infection and community acquired infections; and antibiotic resistance infections due to the organism including but not limited to methicillin-resistant $S$. aureus (MRSA) have been previously reported $[3,6]$. Although $S$. aureus can be present on the skin of the host, a large proportion of its carriage is through the anterior nares of the nasal passages. The ability of the nasal passages to habour $S$. aureus results from a combination of a weakened or defective host and the bacteria's ability to evade host innate immunity [7]. It was estimated that $20 \%$ of the human population are long-term carriers of $S$. aureus. This bacterium is a successful pathogen due to combination of nasal carriage and bacterial immune-evasive strategies. One of these strategies is the production of carotenoid pigment $[2,8]$. $S$. aureus can cause a range of illnesses ranging from minor skin infections such as pimples, impetigo, boils (furuncles), cellulitis folliculitis, carbuncles, scalded skin syndrome, and abscesses, to life-threatening diseases such as pneumonia, meningitis, osteomyelitis, endocarditis, toxic shock syndrome (TSS), bacteremia, and sepsis [2]. Its incidence ranges from skin, soft tissue, respiratory, bone, joint, endovascular to wound infections. Bacterial infections due to $S$. aureus invasion of the host cells and tissues is still one of the five most common causes of nosocomial infections; and the bacterium is often the cause of post-surgical wound infections $[1,9]$. S. aureus infections may spread through contact with pus from an infected wound, skin-to-skin contact with an infected person by producing hyaluronidase that destroys tissues, and contact with objects such as towels, sheets, clothing, or athletic equipment used by an infected person. Staphylococcus aureus is naturally susceptible to virtually every antibiotic that has ever been developed. But antibiotic resistant strains of $S$. aureus is gradually emerging and spreading the community and hospital environment. Infections caused by antibiotic-resistant strains of S. aureus have reached epidemic proportions globally [10]. The overall burden of staphylococcal disease particularly that caused by MRSA is increasing in many countries, in both healthcare and community settings [6]. It is in view of this that this study presumptively determined the antibiogram of $S$. aureus isolates of non-hospital origin.

\section{Materials and methods}

\section{Study area and population}

The study area was Mgbabor community primary school, Abakaliki, Nigeria. A total of 25 apparently healthy primary school pupils in Mgbabor community primary school, Abakaliki were randomly selected and sampled for this study.

\section{Sample collection}

A total of 25 urine samples were collected from each of the 25 pupils recruited for the study. All the biological samples was aseptically collected from the pupils and transported according to all relevant national and international guidelines regarding handling of samples from human subjects. The samples were transported to the microbiology laboratory unit of Ebonyi State University, Abakaliki, Nigeria within one hour.

\section{Culture and identification of Staphylococcus aureus}

Each of the urine samples was aseptically inoculated on mannitol salt agar (MSA) plates and incubated at $37^{\circ} \mathrm{C}$ for $18-24 \mathrm{~h}$ [11]. All culture plates showing significant bacterial growth $(>10$ $\mathrm{CFU} / \mathrm{ml}$ ) were further processed by subculturing onto freshly prepared MSA plates for isolation of pure cultures, and for the identification of $S$. aureus isolates. The isolated colonies growing on the culture media plate was identified based on their colonial characteristics, microscopy, and biochemical testing. S. aureus is Gram positive, coagulase positive, catalase positive, and they produce yellowish colonies on MSA [11].

\section{Antibiotics susceptibility testing}

The antimicrobial susceptibility testing was carried out on Mueller-Hinton ( $\mathrm{MH})$ agar plates as per the guidelines of the Clinical and Laboratory Standard Institute (CLSI) using the modified Kirby-Bauer disk diffusion technique as was previously described [12,13]. Single antibiotic discs including ciprofloxacin $(10 \mu \mathrm{g})$, erythromycin $(10 \mu \mathrm{g})$, levofloxacin $(10 \mu \mathrm{g})$, gentamicin $(10 \mu \mathrm{g})$, ampicillin $(10 \mu \mathrm{g})$, rifampin $(10 \mu \mathrm{g})$, amoxicillin $(10 \mu \mathrm{g})$, streptomycin $(10 \mu \mathrm{g})$, neomycin $(10 \mu \mathrm{g})$ and chloramphenicol $(10$ $\mu \mathrm{g})$ [Oxoid, UK] were used for antimicrobial susceptibility studies. All susceptibility test plates were incubated at $37^{\circ} \mathrm{C}$ for $18-24$ $\mathrm{h}$; and inhibition zone diameter(s) were measured, recorded and interpreted using the standard antibiotic breakpoints recommended by the CLSI [12]. The degree of susceptibility of the isolated Klebsiella species to the tested antibiotics were interpreted as either sensitive $(S)$ or resistant $(R)$ by measuring their respective inhibition zone diameter (IZD) and comparing same to the standard breakpoints of the CLSI.

\section{Statistical analysis}

Data analysis was carried out with the Statistical Package for Social Sciences (SPSS) version 23.0 (SPSS, Chicago, IL, USA) using the $\mathrm{Chi}\left(\mathrm{X}^{2}\right)$ tool. The differences in data were considered statistically significant at $\mathrm{p}<0.05$.

\section{Results}

The prevalence of Staphylococcus aureus isolates in relation to sex is shown in Table 1. In this study, 22 (88\%) pupils out of 25 were shown to be urine culture positive. There were $10(83.3 \%)$ males and 12 (92.3\%) female that were positive. Statistical analysis however shows that this was not statistically significant since $X^{2}$ tab 5.99 $>X^{2}$ cal 0.69 and $P>0.05$ Table 1. Table 2 shows the prevalence of $S$. aureus isolates in this study.

Table 3 shows the distribution of the isolates of $S$. aureus recovered in this study according to the age of the recruited pupils. In males, the overall prevalence of the $S$. aureus isolates was $10(83.8 \%)$, with highest occurrence in those aged 8-10 years 5 (100\%). This was followed by those aged $\leq 7$ years 4 $(80 \%)$ and least in those aged $\geq 12$ years 1 (50\%). In females, the overall prevalence of $S$. aureus isolates was 12 (92.3\%) with highest occurrence in those aged $\leq 7$ years 6 (100\%). This was followed by those aged $8-10$ years 4 (80\%) and least in those 
Table 1 Prevalence of Staphylococcus aureus in relation to sex.

\begin{tabular}{|c|c|c|}
\hline Sex & $X^{2}$ NUMBER EXAMINED 95\% C.I & NUMBER INFECTED \\
\hline Male & 12 & $10(83.3 \%)$ \\
\hline Female & 13 & 12 (92.3\%) \\
\hline Total & 25 & $22(88 \%)$ \\
\hline
\end{tabular}

Table 2 Prevalence of isolated bacterial isolates from urine samples.

\begin{tabular}{|c|c|c|c|}
\hline Isolate & Male (\%) & Female (\%) & Total Number \\
\hline S. aureus & $4(40 \%)$ & 7 (58.3\%) & $11(50 \%)$ \\
\hline & $6(60 \%)$ & $5(41.7 \%)$ & $11(50 \%)$ \\
\hline Total & $10(83.3 \%)$ & $12(92.3 \%)$ & 22 (100\%) \\
\hline
\end{tabular}

Table 3 Distribution of isolated S. aureus according to age.

\begin{tabular}{|c|c|c|c|c|c|c|c|}
\hline $\begin{array}{c}\text { Number Examined } \\
\text { Age }\end{array}$ & Male & Female & $\begin{array}{c}\text { Number Infected } \\
\text { Male }\end{array}$ & Female & $\begin{array}{c}\text { Overall Total } \\
\text { Examined }\end{array}$ & Infected & $X^{2}$ \\
\hline $\begin{array}{c}\text { Infected } \\
\leq 7\end{array}$ & 5 & 6 & $4(80 \%)$ & $6(100 \%)$ & 11 & $10(90.9 \%)$ & \\
\hline $8-10$ & 5 & 5 & $5(100 \%)$ & $4(80 \%)$ & 10 & $9(90.0 \%)$ & \\
\hline$\geq 12$ & 2 & 2 & $1(50 \%)$ & $2(100 \%)$ & 4 & $3(75.0 \%)$ & \\
\hline Total & 12 & 13 & $10(83.3 \%)$ & $12(92.3 \%)$ & 25 & $22(100 \%)$ & 0.05 \\
\hline
\end{tabular}

Table 4 Antibiogram of isolated S. aureus isolates.

\begin{tabular}{|c|c|c|}
\hline Antibiotics & Susceptible n (\%) & Resistant n (\%) \\
\hline Ciprofloxacin & $16(72.7 \%)$ & $6(37.7 \%)$ \\
\hline Erythromycin & $11(50.0 \%)$ & $11(50.0 \%)$ \\
\hline Levofloxacin & $9(40.9 \%)$ & $13(59.0 \%)$ \\
\hline Gentamicin & $17(77.2 \%)$ & $7(31.8 \%)$ \\
\hline Ampicillin & $5(32.7 \%)$ & $17(77.2 \%)$ \\
\hline Rifampin & $0.0(00 \%)$ & $0.0(00 \%)$ \\
\hline Amoxicillin & $10(45.4 \%)$ & $12(54.5 \%)$ \\
\hline Streptomycin & $14(53.6 \%)$ & $8(36.3 \%)$ \\
\hline Neomycin & $0.0(00 \%)$ & $0.0(00 \%)$ \\
\hline Chloramphenicol & $6(37.2 \%)$ & $16(72.7 \%)$ \\
\hline
\end{tabular}

aged $\geq 12$ years $2(100 \%)$. The statistical analysis shows that the occurrence of the $S$. aureus isolates according to the age of the recruited pupils was statistically insignificant $\left(X^{2}\right.$ tab 5.99 $>X^{2}$ cal 0.69 and $P \geq 0.05$ ). The result of the antimicrobial susceptibility profile of the isolated $S$. aureus isolates is shown in Table 4. The S. aureus isolates showed high resistance to ampicillin (77.2\%), chloramphenicol (72.7\%) and levofloxacin (59.0\%). However, they were considerably sensitive to gentamicin $(77.2 \%)$, ciprofloxacin (72.7\%) and streptomycin (53.6\%).

\section{Discussion}

Pathogenic S. aureus have developed resistance to some commonly antimicrobial agents. The emergence and spread of strains of $S$. aureus that are resistant to some first line antibiotics is of public health importance. Staphylococcus aureus is innocuous in most environments but with remarkable adaptability and versatility which has equipped it as a commensal and pathogenic organism. It is one of the most infectious agents with high prevalence in various community- and healthcare-associated infections. In this present study, the prevalence and antibiogram of $S$. aureus isolates bacteriologically recovered from the urine samples of apparently healthy pupils in a local primary school in Abakaliki, Nigeria was presumptively investigated. S. aureus isolates was recovered more from male pupils than the female pupils recruited for this study. The reported prevalence of 22 (88\%) positive urine culture for isolation of $S$. aureus isolates in this study is however higher than the $50 \%$ reported in Kwazulu Natal Province by Shittu and Johnson [5]. The reported highest occurrence of $S$. aureus was found to be higher in females 12 (92.3\%) compared to the males 10 (83.3\%). This result of ours is in agreement with earlier study done by Nkwelang et al. [14] in which $5 \%$ of the urine samples from females analyzed were positive for S. aureus. S. aureus is a normal flora of the human body, but their displacement from its normal site in the body can make them to become pathogenic. The higher occurrence of $S$. aureus isolates in females reported in this study may be accounted for by the fact that the anatomical orientation of females exposes them to easy contamination by the bacterium since this pathogen is endogenously colonizing the vagina vault of healthy women [15]. However, the close proximity of the urethral orifice to the rectum (which is in direct contact with perineal microbes) makes females to be more liable to urinary 
tract infection (UTI) due to $S$. aureus. The improper cleaning of the perineum, the use of napkins and sanitary towel during menstrual period could also be other predisposing factors that make females more prone to infection with the organism. In males, the sterility of the proximal two thirds of the urethra, its longer length and the bactericidal effect of prostatic secretion constitute an excellent immunological defense against bacterial infection. The prevalence of the $S$. aureus isolates recovered in this study in relation to age was observed to be $22(100 \%)$ in males with highest occurrence among those aged 8-10 years 5 (100\%) followed by those aged $\leq 7$ years $4(80 \%)$ and least among those aged $\geq 12$ years 1 (50\%). In females, the occurrence was highest among those aged $\leq 7$ years $6(100 \%)$ followed by those aged $8-10$ years $4(80 \%)$ and least among those aged $\geq 12$ years $2(100 \%)$. The overall prevalence was observed to be higher in females 12 (93.3\%) compared to males 10 (83.3\%). These age brackets consists of children and they are characteristically liable to $S$. aureus infection as a result of poor hygienic practices common amongst children of such age bracket. This data is in

\section{References}

1 Whitt DD, Salyers AA (2002) Bacterial pathogenesis: A Molecular Approach (2014) USA: ASM Press 22: 153.

2 Murray PR, Baron EJ, Jorgenson JH, Pfaller MA, Yolken RH (2003) Manual of clinical Microbiology. Washington, DC, USA 22: 165.

3 Johnsons D, Molling P, Stralin K, Soderquist B (2004) Detection of panton-valentine leukocidin gene in Staphylococcus aureus by Light Cycler PCR: clinical and epidemiological aspects. Clinical Microbiology and Infections, 10: 884-889.

4 Loffer BH, Kahl BC, Grundmeier M, Strangfeld K, Wagner B, et al. (2005) Multiple virulence factors are required for Staphylococcus aureus induced apoptosis in endothelial cells. Cellular Microbiology 7: 1087-1097.

5 Shittu AO, Johnson L (2006) Antimicrobial susceptibility patterns and characterization of clinical isolates of Staphylococcus aureus In Kwazulu Natal Province BMC. Infectious Diseases 6: 125.

6 Kaplan SL (2005) Three year surveillance of community-acquired Staphylococcus aureus infections in children. Clinical Infectious Diseases 40: 1785-1791.

7 Quinn GA, Cole AM (2007) Suppression of innate immunity by a nasal carriage strain of Staphylococcus aureus increases its colonization on nasal epithelium immunology, Epithelium immunology 122: 80-89.

8 Lowy FD (1998) Staphylococcus aureus infection. N Engl J Med 339: 520-532.

9 Ryan KJ, Ray CG (2004) Sherries Medical Microbilogy. McGraw Hill 123. accordance with earlier reports by Nkwelang et al. [14]. The $S$. aureus isolates showed highest resistance to ampicillin (77.2\%) and chloramphenicol (72.2\%). But the isolates were found to be susceptible to gentamicin (77.2\%) and ciprofloxacin $(72.7 \%)$. The resistance and susceptibility profile of the $S$. aureus isolates recovered in this study conforms to previous reports that $S$. aureus is notoriously resistant to some commonly used antimicrobial agents including ampicillin and chloramphenicol which may be clinically used for the treatment of infections caused by this organism $[5,16,17]$.

\section{Conclusion}

The results of this study have shown that the $S$. aureus isolates recovered from apparently healthy pupils are resistant to some commonly used antibiotics. This study highlights the need for continuous surveillance of the occurrence and antibiogram of Staphylococcus aureus with the view to containing any disease outbreak due to them.

10 Panagea S, Perry JD, Gould FK (2001) Treatment of S. aureus with clindamycin. Journal of Antimicrobial Chemotherapy 44: 581-582.

11 Cheesbrough M (2006) District laboratory practice in tropical countries part 2, Cambridge University press. New York 12: 248-266.

12 Clinical Laboratory Standard Institute (CLSI). Performance standards for antimicrobial disk susceptibility test (2011) Fifteenth informational supplement, CLSI document M100-S15, Wayne, USA 112.

13 Ejikeugwu C, Iroha I, Amaechi CO, Ugwu M, Eze P, et al. (2017) Multiple Antibiotic Resistance, Antibiogram and Phenotypic Detection of Metallo-Beta-Lactamase (MBL) from Escherichia coli of Poultry Origin. Journal of Applied Microbiology and Biochemistry 1: 1-6.

14 Nkwelang H, Grace G, Akochere JT, Kanga LH, Nfoncham ED, et al. (2009) Staphylococcus aureus isolates from clinical samples in a semi-rural area of Cameroon: phenotypic characteristics of isolates. African Journal of Microbial Research 3: 731-736.

15 Warner J, Onderdonk B (2004) Diversity of toxic shock syndrome toxin 1-positive Staphylococcus aureus isolates. Applied Environmental Microbiology 70: 6931-6935.

16 Joshi AU, Adewuyi IK, Collins LV (2013) Antibiogram and Betalactamase production of Staphylococcus aureus isolates from different Human clinical specimens in a tertiary health institution in Ile-ife, Nigeria. American-Eurosian Journal of Scientific Research 5: 230-233.

17 Hashimotor DO, Bisi-Johnson MA, Shittu AO (2006) Epidemiological analysis of clinical isolates Staphylococcus aureus in lle-ife, Nigeria. Pakistan Journal of Biological Science 8: 1016-1020. 